Artigo original

Hegemonia - Revista Eletrônica de Relações Internacionais do Centro Universitário Unieuro

ISSN: $1809-1261$

UNIEURO, Brasília, número 13, 2014, pp 99-128.

Recebido em: 22/3/2014

Avaliado em:17/4/2014

Aprovado em: 14/5/2014

\title{
Política de crédito rural para o desenvolvimento da agricultura
}

\section{familiar sustentável}

OLIVEIRA, Michel Angelo Constantino de ${ }^{1}$

RESUMO: A série de recursos do Pronaf vem evoluindo a cada ano, distribuindo para mais agricultores e promovendo mudanças no cenário agrícola. Essas mudanças estruturais do Pronaf foram discutidas nesse artigo, que teve como objetivo analisar a nova política pública federal de crédito rural para o desenvolvimento da agricultura familiar sustentável, pois o Governo Federal a partir de 2003 criou linhas de créditos diferenciadas e de cunho sustentável que tem como público alvo os produtores familiares. Os objetivos desse estudo foram de relatar as características das linhas de crédito verdes, observando seus critérios, montantes e resultados esperados. Os dados utilizados foram séries históricas do Pronaf total, e do Pronaf verde, disponibilizadas pelo MDA, MAPA e Banco Central do Brasil. Concluiu-se através dos dados que os esforços efetuados em relação ao Pronaf foram intensos e com aporte recursal de grande proporção. A política de crédito nacional percebeu sua importância para o setor agropecuário e acionou subsídios importantes para o crescimento setorial e regional com viés de sustentabilidade, porém desafios na aplicação e uso do crédito ainda existem, pois os recursos destinados ao Pronaf Verde são praticamente insignificantes em relação ao Pronaf geral.

Palavras-chave: Pronaf; Pronaf verde; Sustentabilidade; Agricultura Familiar.

ABSTRACT: The series features Pronaf is evolving every year, spreading to more farmers and promoting changes in the agricultural setting. These structural changes Pronaf were discussed in the paper, which aimed to analyze the new federal public policy for rural credit for the development of sustainable family farming, because the Federal Government since 2003 has created credit lines differentiated and sustainable nature that

\footnotetext{
${ }^{1}$ Professor da Universidade Católica Dom Bosco - UCDB.
} 
Artigo original

Hegemonia - Revista Eletrônica de Relações Internacionais do Centro Universitário Unieuro

ISSN: $1809-1261$

UNIEURO, Brasília, número 13, 2014, pp 99-128.

has as target family farmers. The objectives of this study were to report the characteristics of the green lines of credit, noting their criteria, amounts and expected results. The data were time series of total Pronaf and Pronaf green, provided by MDA, MAP and Central Bank of Brazil. It was concluded from the data that the efforts made in relation to Pronaf were intense and appellate contribution of great proportion. The policy of national credit realized its importance to the agricultural sector and triggered important support for growth sectors and regions with a bias of sustainability, but challenges in the implementation and use of credit still exist because the resources devoted to Pronaf Green are almost insignificant in comparison to Pronaf general.

Key-words: Pronaf; Pronaf green; Sustainability; Family Agriculture.

\section{Introdução}

A construção de uma nova consciência social sustentável preterida na Eco-92 ecoou na ultima década no âmbito das políticas públicas voltadas para o campo. As mudanças ocorridas no direcionamento dos resultados práticos ligados ao uso de recursos financeiros advindos de políticas públicas com caráter para o desenvolvimento sustentável estão promovendo novas regras e criando novos cenários para o Brasil rural.

Inevitavelmente, pelas mudanças climáticas, ambientais e sociais ocorridas no mundo, os formuladores de políticas públicas de crédito agrícola vêm tentando equilibrar os ganhos de produtividade com práticas de produção ambientalmente corretas. O cenário de catástrofes ambientais tem promovido debates que influenciam todos os elos da cadeia produtiva, desde o pequeno produtor aos policy makers.

O agronegócio brasileiro representa perto de $30 \%$ do PIB nacional, sendo também responsável por pouco mais de um terço das exportações e dos empregos nacionais. Do total do agronegócio brasileiro, um terço provém da agricultura familiar (MDA, 2006). Frente à importância da agricultura familiar no Brasil, estudar as determinantes de seu desenvolvimento é participar das transformações que vem afetando o 
Artigo original

Hegemonia - Revista Eletrônica de Relações Internacionais do Centro Universitário Unieuro

ISSN: $1809-1261$

UNIEURO, Brasília, número 13, 2014, pp 99-128.

setor produtivo, no caso de políticas públicas voltadas ao campo, é compreender as novas institucionalidades.

De acordo com o Sistema Nacional de Crédito as operações contratadas de crédito rural vêm crescendo exponencialmente ao longo do tempo. A criação do Programa Nacional de Fortalecimento da Agricultura Familiar em 1996 com a finalidade de prover crédito agrícola e apoio institucional aos pequenos produtores rurais, o cenário desde então muda e se estrutura em torno de um segmento importante para o desenvolvimento da economia brasileira.

A agricultura familiar está em destaque quando se analisa os montantes do Programa Nacional de Fortalecimento da Agricultura Familiar - PRONAF, sua série de recursos vem evoluindo a cada ano, distribuindo para mais agricultores e promovendo mudanças no cenário agrícola. Essas mudanças estruturais do PRONAF serão discutidas nesse artigo, que teve como objetivo analisar a nova política de crédito rural para o desenvolvimento da agricultura familiar sustentável, pois o Governo Federal a partir de 2003 criou linhas de créditos verdes, ou seja, diferenciadas e de cunho sustentável que tem como público alvo os produtores familiares. Os objetivos específicos desse estudo foram de relatar as características das linhas de crédito verdes, observando seus critérios, montantes e resultados esperados. Os dados utilizados foram séries históricas do PRONAF total, e do PRONAF VERDE, disponibilizadas pelo Ministério do Desenvolvimento Agrário (MDA), Ministério da Agricultura Pecuária e Abastecimento (MAPA) e do Banco Central do Brasil (BCB).

2 Referencial teórico

A agricultura familiar é conhecida como uma agricultura de baixo impacto ambiental e de proporções positivas com relação a aspectos 
Artigo original

Hegemonia - Revista Eletrônica de Relações Internacionais do Centro Universitário Unieuro

ISSN: 1809-1261

UNIEURO, Brasília, número 13, 2014, pp 99-128.

sociais, culturais e econômicos. Os determinantes de crescimento da agricultura são listados na literatura como sua produtividade total dos fatores, que analisam trabalho, terra, tecnologia e produção. No caso da agricultura familiar, outros fatores além da PTF determinam seu desempenho, como por exemplo, a continuidade da família no campo, sua renda, seu bem estar e a sustentabilidade da produção.

O agronegócio brasileiro representa perto de 30\% do PIB nacional, sendo também responsável por pouco mais de um terço das exportações e dos empregos nacionais. Do total do agronegócio brasileiro, um terço provém da agricultura familiar (MDA, 2006).

Frente à importância da agricultura familiar no Brasil, as comparações de produtividade e perspectivas desse segmento do agronegócio em relação à agricultura patronal vêm crescendo. Após o senso de 2006 realizado pelo IBGE, muito se tem discutido sobre a importância da agricultura familiar no desenvolvimento econômico e social do país.

Tradicionalmente, considera-se que a agricultura familiar participa mais da produção nacional de alimentos, enquanto a agricultura patronal é mais focalizada em produtos de exportação. Gualda (2003) afirma que o modelo patronal ou agro-exportador volta-se prioritariamente para a produção em alta escala, visando a expansão da produção, com ganhos crescentes em produtividade. Através de constante incorporação de tecnologia procura aumentar sua competitividade junto aos mercados internacionais, assegurando ao Brasil a primeira posição no ranking de produção e exportação de vários produtos agropecuários.

Vilpoux et al (2010) a agricultura familiar deverá se modernizar. Essa constatação vai de acordo com a afirmação de Wilkinson (2008), que escreve que para a agricultura familiar se manter nas grandes cadeias de commodities ela precisa alcançar novos níveis de qualidade e novas escalas de produção. Caso contrário, a agricultura patronal, mais 


\section{Artigo original}

Hegemonia - Revista Eletrônica de Relações Internacionais do Centro Universitário Unieuro

ISSN: $1809-1261$

UNIEURO, Brasília, número 13, 2014, pp 99-128.

tecnificada deverá predominar cada vez mais, pois será a única capaz de acompanhar as novas necessidades de produção. Nesse contexto o crédito rural para investimentos é fundamental para transformar o pequeno produtor em um negócio produtivo mais eficiente e que tenha como base o progresso tecnológico de maneira sustentável.

A demanda global por alimentos é diretamente influenciada pelos consumos humanos e animal, pelo uso industrial e pela reposição dos estoques. A população e a renda dos indivíduos são os fatores de maior impacto sobre o consumo de alimentos. Maior a população, maior a quantidade de alimentos necessários para suprir as necessidades dessa população. Em paralelo, o crescimento da renda aumenta o consumo de carne e de produtos processados, incrementando ainda mais as necessidades de alimentos (VILPOUX \& OLIVEIRA, 2011). A Figura 1.1 indica o crescimento da população mundial nos últimos 250 anos, com previsões até 2050. Essa Figura mostra a aceleração do crescimento demográfico a partir da segunda metade do século $X X$. A estimativa é de uma estabilização da população em torno de 9 bilhões de habitantes na metade do século. Assim, o agronegócio mundial deverá encontrar recursos suficientes para nutrir esses 2,5 bilhões de pessoas suplementares. Dados de Charles et al. (2010) sugerem que o mundo precisará de 70 a 100\% mais alimentos até 2050. Para conseguir atender a demanda, a produção de cereais deverá crescer em torno de $50 \%$ de 2000 a 2030, enquanto que o crescimento necessário da produção de carne deverá ser de 85\%, sem contar as necessidades crescentes para biocombustíveis (THE WORLD BANK, 2008). 
Artigo original

Hegemonia - Revista Eletrônica de Relações Internacionais do Centro Universitário Unieuro

ISSN: $1809-1261$

UNIEURO, Brasília, número 13, 2014, pp 99-128.

Figura 1.1. Evolução da população mundial, entre 1750 e 2050

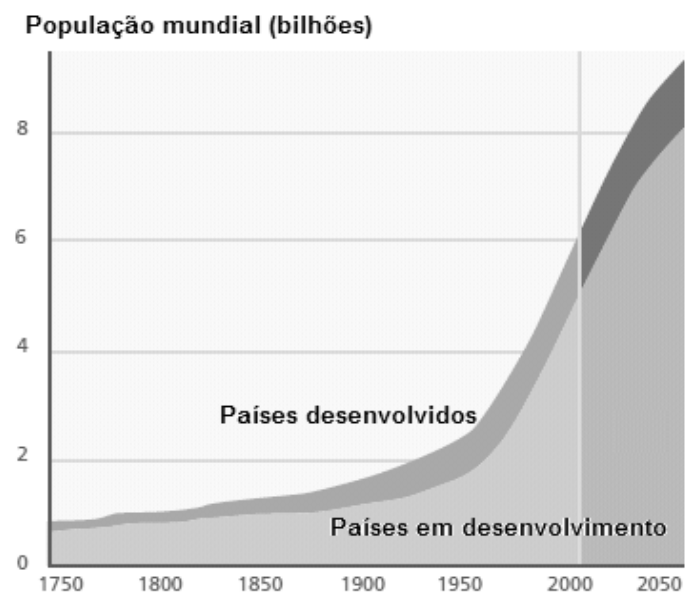

Fonte: Land commodities (2009).

Nos últimos cinqüenta anos, o crescimento de população ocorreu principalmente os países menos desenvolvidos. Na maioria desses países, o nível de renda cresceu de forma acelerada nesse período, e deverá continuar crescendo nas próximas décadas. Esse crescimento significa maior consumo por habitante, com necessidade de aumento ainda maior da produção e mudança nos padrões de consumo, principalmente com elevação do consumo de carne.

Além da demanda na alimentação humana e animal, a produção agrícola está entrando cada vez mais no mercado de bioenergia. Em nível mundial, $12 \%$ da produção de milho foram usadas na produção de etanol em 2007 (FAO, 2009a). Mesmo se essa proporção permanece bem inferior ao uso mundial de milho para alimentação animal, que era de $60 \%$ no mesmo ano, o mercado de bioenergia é relativamente novo e deve crescer cada vez mais. A demanda para matérias-primas agrícolas destinadas a produção de bioenergia explodiu nos últimos anos (Figura 1.2) e pode 
Artigo original

Hegemonia - Revista Eletrônica de Relações Internacionais do Centro Universitário Unieuro

ISSN: $1809-1261$

UNIEURO, Brasília, número 13, 2014, pp 99-128.

criar um desequilibro na produção alimentar mundial, com diminuição da área disponível para produção de alimentos.

Figura 1.2. Evolução da produção mundial de bicombustíveis, entre 1975 e 2005

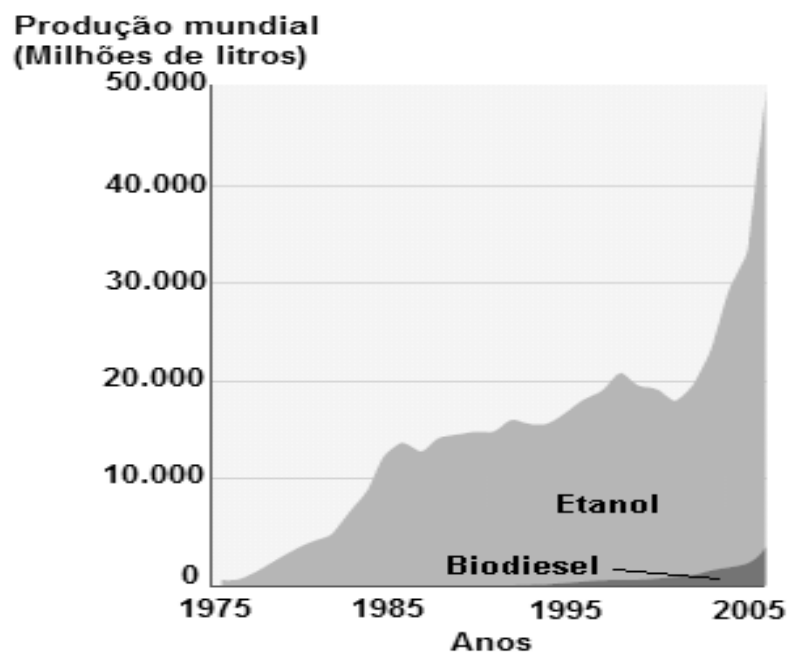

Fonte: Land commodities (2009)

Apesar da produção mundial de grãos terem mais do que dobrada nos últimos 50 anos, o crescimento da área agrícola cresceu apenas $9 \%$. No futuro, o aumento da área agriculturável vai ser cada vez mais complicado, principalmente frente às necessidades cada vez maior de proteção do meio ambiente. Em consequência, é de se esperar que mais alimentos deverão ser produzidos a partir de uma área estável ou mesmo decrescente (Figura 1.3). 
Artigo original

Hegemonia - Revista Eletrônica de Relações Internacionais do Centro Universitário Unieuro

ISSN: $1809-1261$

UNIEURO, Brasília, número 13, 2014, pp 99-128.

Figura 1.3. Evolução da área disponível para agropecuária, no mundo e por habitante, entre 1700 e 2007 e previsões até 2050

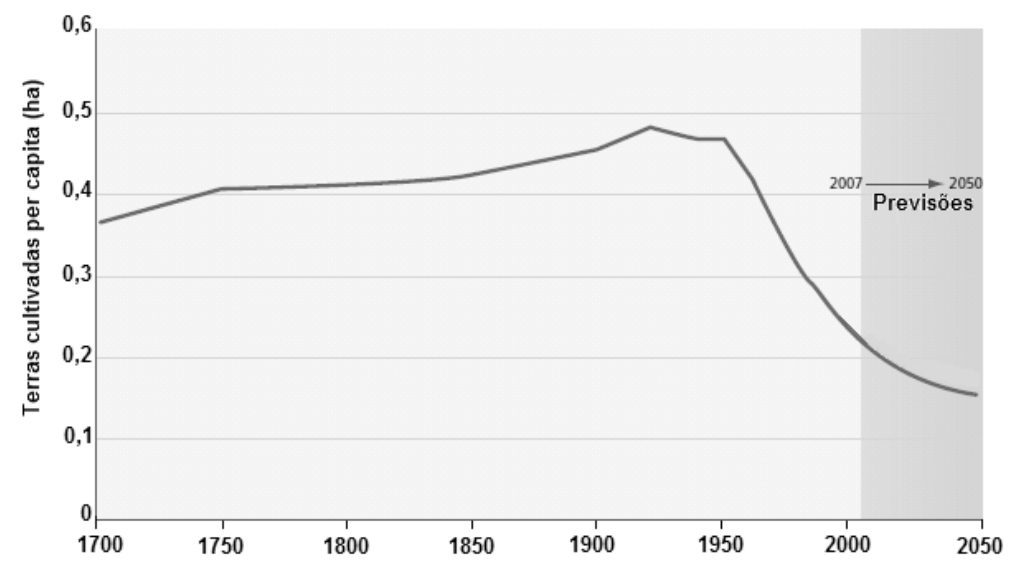

Fonte: Land commodities (2009)

De um total de 0,22 hectares por pessoa em 2007, a disponibilidade de terra para alimentar uma pessoa deverá passar para 0,15 em 2050. Assim, um hectare que alimenta hoje 4,5 pessoas deverá alimentar um pouco mais de 6,5 em 2050.

Para os especialistas, o único modo de acompanhar as necessidades de abastecimento em alimento é com o uso de novas tecnologias para os produtores mais modernos e de processos mais tecnificados para os produtores com produtividades reduzidas. Entre as novas tecnologias, Fedorroff et al. (2010) citam o aumento do melhoramento tradicional e genético, mas também o uso crescente dos Organismos Geneticamente Modificados (OGM).

A adição de tecnologia no campo como afirmam os autores acima citados é sobremaneira dedicada na literatura de economia agrícola, como tal, outro ponto importante é o uso sustentável dos recursos naturais. 
Artigo original

Hegemonia - Revista Eletrônica de Relações Internacionais do Centro Universitário Unieuro

ISSN: $1809-1261$

UNIEURO, Brasília, número 13, 2014, pp 99-128.

Para esse último critério, o mundo vem propondo mudanças radicais no modo de vida e na produção de alimentos, em reuniões com chefes de estado, a sustentabilidade é debatida como nova onda de políticas regionais, nacionais e mundiais para a minimização de impactos ambientais e formas sistemáticas de uso dos recursos.

Para autores ligados à sustentabilidade e desenvolvimento sustentável da agricultura, a agricultura familiar se desponta como forma organizacional mais próxima do modelo sustentável de produção, proporcionando um incremento econômico e social fundamental para o equilíbrio da produção de alimentos. A agricultura familiar ocupa lugar de destaque na produção de aves e suínos, grandes produtos de exportação, e é minoritária na produção de arroz, alimento de base do brasileiro (Figura 1.4).

Figura 1.4. Percentagem da produção de vários produtos agropecuários oriundos da agricultura familiar

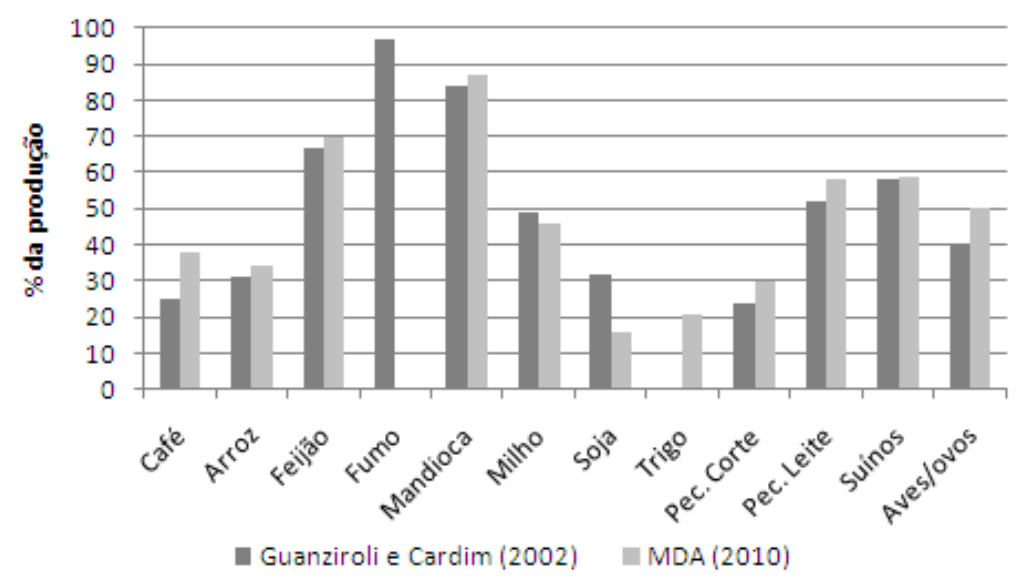

Fonte: Guanziroli e Cardim (2002) e MDA (2010).

Os dados da Figura 1.4 comprovam a importância da agricultura familiar para a alimentação da população, mas evidencia também a forte 
Artigo original

Hegemonia - Revista Eletrônica de Relações Internacionais do Centro Universitário Unieuro

ISSN: 1809-1261

UNIEURO, Brasília, número 13, 2014, pp 99-128.

presença desse tipo de produtores em produções não alimentares, como o fumo, ou em produtos típicos de exportação, como café, soja e pecuária de corte.

Mais importante que a produção de alimentos, a capacidade de produzir de modo eficiente torna-se um aspecto cada vez mais relevante. Nesse contexto, as políticas públicas devem ir de encontro com a ampliação da capacidade do agricultor familiar em acompanhar as mudanças tecnológicas, no caso do crédito rural é possível fazer investimentos na capacitação e produção agrícola, garantindo a sobrevivência da agricultura familiar como atividade de interesse para a população em geral.

2.1 Programa nacional de fortalecimento da agricultura familiar - PRONAF

Os pequenos produtores ou agricultores familiares são de alguma forma marginalizada pelas novas tecnologias e redes de comercialização. O papel da agricultura familiar tem apoio no constructo social e econômico das famílias e da economia nacional. O direcionamento de crédito agrícola em geral foi de promover uma inserção dos grupos marginalizados para potencializar a razão do desenvolvimento. Além de gerar renda e emprego a política de crédito incorpora segmentos indutores ou externalidades positivas como minimização do êxodo rural, investimentos em tecnologia e competitividade no longo prazo.

Até a criação do PRONAF não havia linha de crédito específica para a agricultura familiar, sendo que tais produtores competiam com produtores mais capitalizados e inseridos na revolução verde. Porém o Sistema Nacional de Crédito Rural (SNCR) foi criado em 1966 e tinha como função prover condições de pagamento compatíveis com as especificidades do setor rural, mediante taxas de juros favorecidas. 
Artigo original

Hegemonia - Revista Eletrônica de Relações Internacionais do Centro Universitário Unieuro

ISSN: $1809-1261$

UNIEURO, Brasília, número 13, 2014, pp 99-128.

Analisando dados do Sistema Financeiro Nacional de 2000-2012, com corte ao crédito agrícola geral, tem-se uma evolução exponencial das operações de créditos rurais nacionais como mostra a Figura 1.5.

Figura 1.5. Evolução das operações de crédito rural do sistema financeiro

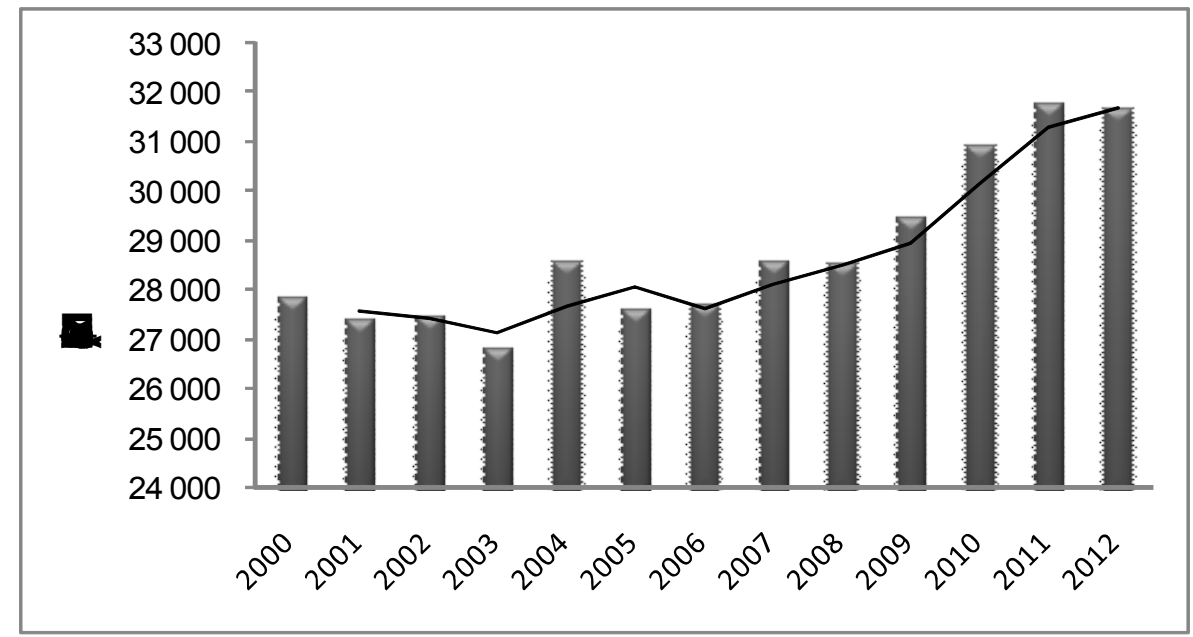

Fonte: Banco Central do Brasil (2012).

O Programa Nacional de Fortalecimento da Agricultura Familiar (PRONAF) foi criado em 1996 com a finalidade de prover crédito agrícola e apoio institucional aos pequenos produtores rurais. Sua criação se deu em resposta às pressões dos sindicatos e movimentos sociais rurais diante das sérias dificuldades que os pequenos agricultores encontravam para se manter no campo devido ao modelo de desenvolvimento agrícola brasileiro, altamente concentrador de terras e renda e cada vez mais dependente de insumos e tecnologias industriais. Ao longo dos seus anos de existência, apesar dos impactos positivos observados na esfera econômica, promovendo um aumento expressivo da produção nos segmentos da agricultura familiar apoiados por sua política de crédito, o 
Artigo original

Hegemonia - Revista Eletrônica de Relações Internacionais do Centro Universitário Unieuro

ISSN: 1809-1261

UNIEURO, Brasília, número 13, 2014, pp 99-128.

PRONAF sofreu várias críticas por não ter sido capaz de estimular uma mudança efetiva no modelo de desenvolvimento agropecuário brasileiro (SAMBUICHI \& OLIVEIRA, 2011).

De acordo com MDA (2009), o PRONAF "financia projetos individuais ou coletivos, que gerem renda aos agricultores familiares e assentados da reforma agrária". Para um agricultor entrar no programa, ele deve primeiro discutir o que será financiado, seja o custeio da safra ou os investimentos em máquinas e implementos agrícolas. Tomada esta decisão, o produtor rural deve procurar algum sindicato rural ou a Empresa de Assistência Técnica e Extensão Rural (EMATER) para obter sua Declaração de Aptidão ao PRONAF (DAP). Esta é emitida segundo a renda do produtor e o tipo de atividade e o direciona para uma das linhas de crédito do programa.

Subsidiar o produtor familiar ou a comunidade rural familiar com crédito diferenciado é uma política intervencionista que promove desenvolvimento a partir da geração de inovações e oportunidades relacionadas com os critérios e objetivos do programa utilizado. As organizações coletivas como cooperativas, associações, grupos organizados, arranjos produtivos locais e comunidades, devem participar desse movimento estrutural de crescimento do crédito subsidiado, para tanto é preciso atender às expectativas da população que necessita de respostas sustentáveis aos problemas e tragédias ambientais que vem ocorrendo através das mudanças climáticas mundiais.

Os recursos do PRONAF evoluíram após sua criação, seus montantes não são utilizados $100 \%$, há ainda alguns gargalos e desafios para a política de crédito. Conforme dados do Ministério do Desenvolvimento Agrário (2011) os percentuais realizados, ou seja, contratados pelos produtores rurais entre as safras de 1999-2000 a 20082009 são: 
Artigo original

Hegemonia - Revista Eletrônica de Relações Internacionais do Centro Universitário Unieuro

ISSN: $1809-1261$

UNIEURO, Brasília, número 13, 2014, pp 99-128.

Figura 1.6 Percentual de contratação do crédito PRONAF

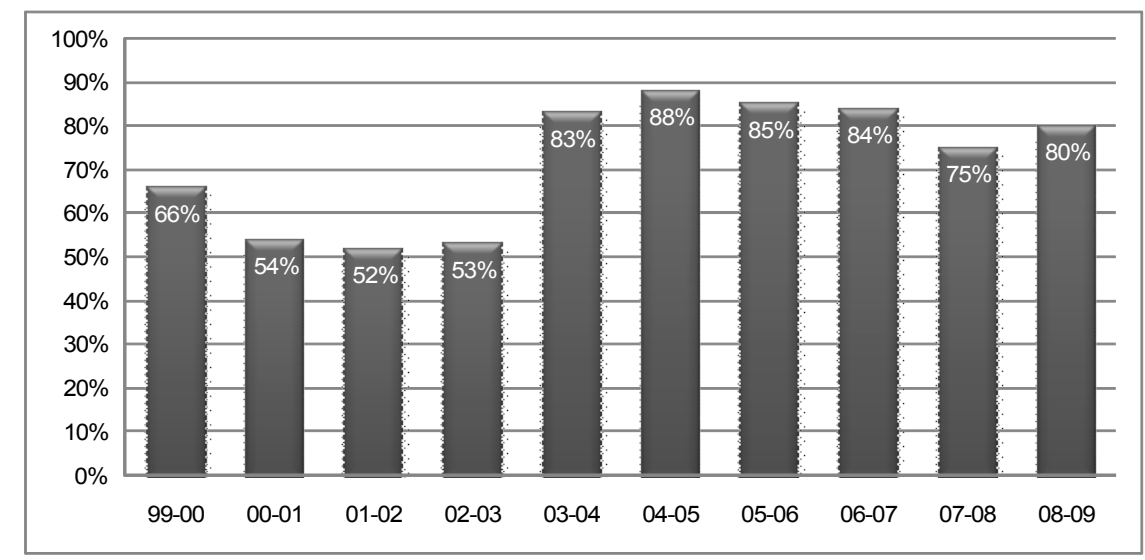

Fonte: Dados SAF/MDA (2011)

De acordo com a Figura 1.6 o percentual de contratação ainda é um desafio crítico para a política de crédito rural brasileira. Apesar dos percentuais melhorarem significativamente a partir da safra 2003-2004, o crédito disponível deve ser utilizado para garantir a eficiência do programa.

Os recursos destinados ao PRONAF são altos, e vem evoluindo a cada ano, a Figura 1.7 mostra essa evolução em valores por safra agrícola.

Figura 1.7 Montante do PRONAF disponibilizado por safraFigura 1.7 Montante do PRONAF disponibilizado por safra

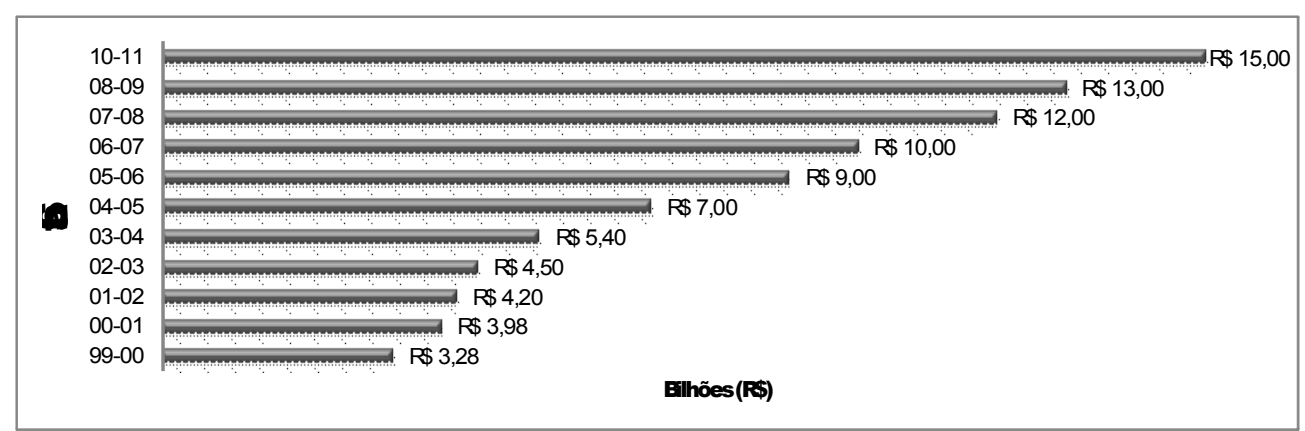

Fonte: Dados SAF/MDA (2011) 
Artigo original

Hegemonia - Revista Eletrônica de Relações Internacionais do Centro Universitário Unieuro

ISSN: $1809-1261$

UNIEURO, Brasília, número 13, 2014, pp 99-128.

Os dados mostram que o crescimento dos recursos disponibilizados é constante, estão evoluindo exponencialmente em valores reais. Os dados indicam grande preocupação do Governo Federal na disponibilização de ativos que possam tornar mais exequível os projetos relacionados com o Brasil rural.

Dentro da perspectiva de crescimento através de subsídios como é o PRONAF veio à mudança em torno da sustentabilidade das ações e programas submetidos pelo Governo Federal diante dos desafios do século XXI de garantir recursos para as próximas gerações.

Com a pressão de países desenvolvidos e organizações não governamentais, discussões foram iniciadas para avaliar qual o modelo de crescimento ideal e quais as políticas e ações afirmativas para diminuir os impactos causados pelos homens no ambiente.

Desde a promoção da ECO-92 outros encontros são realizados sistematicamente entre líderes mundiais para discutir novos rumos da economia mundial e estratégias para mitigação das crises no meio ambiente. Nesse contexto cada país iniciou mudanças nas políticas públicas. No caso da política de crédito brasileira, foco desse estudo, o Ministério do Desenvolvimento Agrário através da Secretaria de Agricultura Familiar decidiu criar novas institucionalidades para o PRONAF, subdividindo o crédito em linhas diferenciadas. Essas linhas pretendem ter um impacto produtivo relacionado intimamente com a sustentabilidade ambiental das ações dos contratantes.

\subsection{Linhas de crédito diferenciadas}

Esse item discorre sobre uma nova nomenclatura para as linhas de crédito diferenciadas do Programa de Fortalecimento da Agricultura 
Artigo original

Hegemonia - Revista Eletrônica de Relações Internacionais do Centro Universitário Unieuro

ISSN: $1809-1261$

UNIEURO, Brasília, número 13, 2014, pp 99-128.

Familiar. As linhas estudadas são Pronaf Agroecologia, Pronaf Floresta, Pronaf Semi-árido e Pronaf Eco. O conjunto dessas linhas que fazem parte do Pronaf geral é chamado de PRONAF VERDE.

Figura 1.8 PRONAF VERDE e sua composição

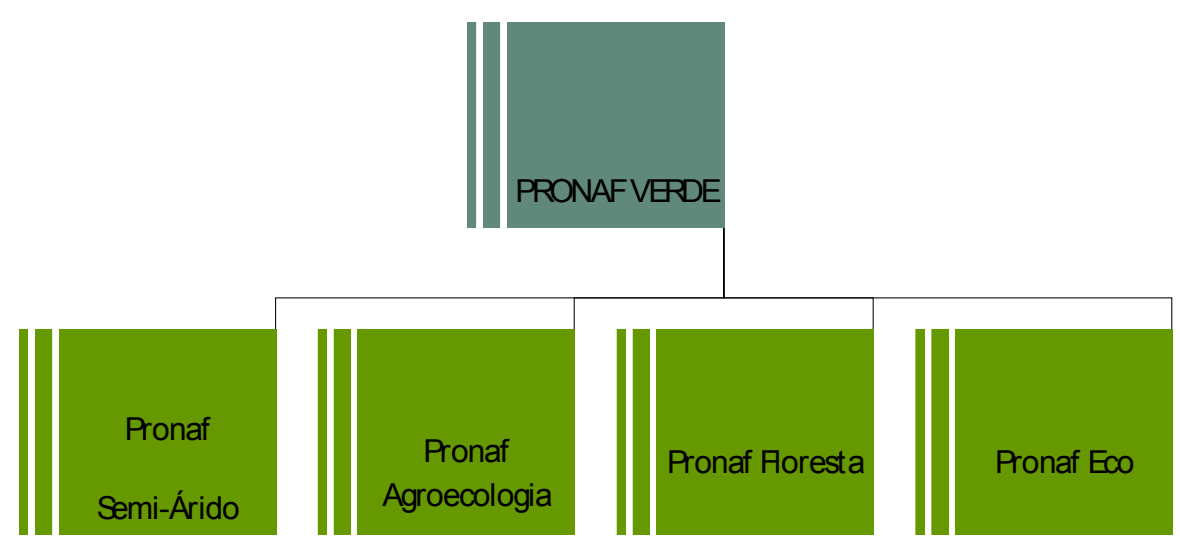

A Figura 1.8 mostra a composição do PRONAF VERDE, são quatro linhas especiais de cunho sustentável. Essas linhas de crédito do Pronaf que compõem o Pronaf Verde são os campos empíricos de estudo, pois seus diferenciais de contratação, critérios e objetivos vão de encontro com uma política capaz de mudar os modos convencionais de produção, escala e desempenho para o desenvolvimento sustentável.

O grupo de linhas de crédito que compõe o Pronaf Verde tem em comum o objetivo de maximizar o uso dos recursos naturais nas propriedades rurais, ampliando o uso de práticas conservacionistas e investindo em alternativas sustentáveis de produção como a agroecologia, produção orgânica, transição agroflorestal e outros.

A economia verde foi incluída na pauta das políticas agrícolas, e para reforçar os esforços realizados nessa economia, foram criadas, a partir de 2003, novas linhas de crédito de investimento como o Pronaf Agroecologia, Pronaf Floresta, Pronaf Semi-árido e Pronaf Eco, para 
Artigo original

Hegemonia - Revista Eletrônica de Relações Internacionais do Centro Universitário Unieuro

ISSN: $1809-1261$

UNIEURO, Brasília, número 13, 2014, pp 99-128.

incentivar a transição para um modelo agrícola mais sustentável. O quadro abaixo mostra resumidamente os objetivos de cada programa de crédito que compõe o Pronaf Verde.

Quadro 1: Objetivo das linhas de crédito que compõe o Pronaf Verde

\begin{tabular}{|l|l|}
\hline \multicolumn{2}{|l|}{ PRONAF VERDE } \\
\hline $\begin{array}{l}\text { para } \\
\text { Investimento }\end{array}$ & \multicolumn{1}{|c|}{ Objetivo } \\
\hline $\begin{array}{l}\text { Pronaf } \\
\text { Agroecologia }\end{array}$ & $\begin{array}{l}\text { Financiar a implantação e manutenção de sistemas } \\
\text { agroecológicos de produção, conforme normas } \\
\text { estabelecidas pela Secretaria da Agricultura Familiar } \\
\text { do Ministério do Desenvolvimento Agrário (MDA), e } \\
\text { sistemas orgânicos de produção, conforme normas } \\
\text { estabelecidas pelo Ministério da Agricultura, Pecuária } \\
\text { e Abastecimento (MAPA) }\end{array}$ \\
\hline Pronaf Floresta & $\begin{array}{l}\text { Financiar a implantação e manutenção de sistemas } \\
\text { agroflorestais, manejo florestal e exploração } \\
\text { extrativista ecologicamente sustentável, áreas de } \\
\text { preservação permanente, reserva legal, recuperação } \\
\text { de áreas degradadas e enriquecimento de áreas que } \\
\text { já apresentam cobertura florestal diversificada com } \\
\text { espécies nativas }\end{array}$ \\
\hline $\begin{array}{l}\text { Financiar investimentos em projetos de convivência } \\
\text { com o semi-árido, focando na sustentabilidade dos } \\
\text { agroecossistemas e priorizando projetos de infra- } \\
\text { estrutura hídrica e implantação, ampliação, }\end{array}$
\end{tabular}


Artigo original

Hegemonia - Revista Eletrônica de Relações Internacionais do Centro Universitário Unieuro

ISSN: $1809-1261$

UNIEURO, Brasília, número 13, 2014, pp 99-128.

\begin{tabular}{|l|l|}
\hline \multirow{3}{*}{ Pronaf Eco } & $\begin{array}{l}\text { recuperação ou modernização das demais infra- } \\
\text { estruturas }\end{array}$ \\
\hline & $\begin{array}{l}\text { Financiar a implantação, utilização e/ou recuperação } \\
\text { de tecnologias para produção de energia renovável, } \\
\text { tecnologias ambientais, sistemas de armazenamento } \\
\text { hídrico, silvicultura e a adoção de práticas } \\
\text { conservacionistas e de correção da acidez e } \\
\text { fertilidade do solo }\end{array}$ \\
\hline
\end{tabular}

Entende-se que as linhas de crédito que compõe o Pronaf Verde são inovações na política agrícola brasileira que busca novos resultados para as ações sustentáveis no âmbito ambiental da agricultura. Uma análise criteriosa dos parâmetros e montantes realizados é computada na análise dos resultados permitindo contribuir para averiguação dos resultados desses programas específicos que pode objetiva mudar 0 paradigma do modelo de desenvolvimento agropecuário brasileiro.

$\mathrm{Na}$ próxima seção está detalhada a metodologia de pesquisa realizada no estudo, onde busca atender os objetivos relacionados aos resultados esperados e hipóteses.

3. Método de pesquisa

Para 0 alcance dos resultados foram realizadas pesquisas bibliográficas sobre cada linha de crédito específica que compõe o Pronaf Verde. Além da literatura sobre o tema, foram analisados textos de discussão divulgados pelo Instituto de Pesquisa Econômica Aplicada IPEA, além de dados dos Planos Plurianuais (PPA) dos Ministérios do Desenvolvimento Agrário, Ministério do Meio Ambiente e Ministério da 
Artigo original

Hegemonia - Revista Eletrônica de Relações Internacionais do Centro Universitário Unieuro

ISSN: $1809-1261$

UNIEURO, Brasília, número 13, 2014, pp 99-128.

Agricultura Pecuária e Abastecimento. Os dados quantitativos foram obtidos diretamente nos Ministérios, sendo que montantes do PRONAF a Secretaria de Agricultura Familiar (SAF/MDA) disponibilizou para pesquisa, além dos dados divulgados pelo Banco Central do Brasil (BCB). A metodologia utilizada tem como objetivo a confrontação dos dados publicados com os objetivos da linha de crédito, analisando suas características resultados e prováveis impactos para setor produtivo dos produtores de base econômica familiar.

\section{Apresentação e discussão dos resultados}

Nesse item a análise recai nos montantes destinados a cada linha de crédito do Pronaf Verde a partir da criação de cada linha e disponibilização dos recursos para o uso do seu público alvo.

No Quadro 2 é possível visualizar os valores de cada linha e sua evolução a partir da data de operacionalização dos recursos e ainda o resultado total do Pronaf Verde.

Quadro 2: Montantes do PRONAF Verde.

\begin{tabular}{|ccccc|}
\hline & $\begin{array}{c}\text { Agroecol } \\
\text { ogia }\end{array}$ & Eco & $\begin{array}{c}\text { Flores } \\
\text { ta }\end{array}$ & $\begin{array}{c}\text { Semi- } \\
\text { árido }\end{array}$ \\
\hline 2004 & - & - & 8,4 & 15,4 \\
2005 & 0,61 & - & 15,5 & 47,9 \\
2006 & 2,52 & - & 25,3 & 45,6 \\
2007 & 1,96 & 2,69 & 12,7 & 37,6 \\
2008 & 5,05 & 18,63 & 7,3 & 24,4 \\
2009 & 1,26 & 18,97 & 5,9 & 17,5 \\
\hline Total & R\$ 315,1 milhões \\
\hline
\end{tabular}

Fonte de Dados: MDA/SAF (2011) 
Artigo original

Hegemonia - Revista Eletrônica de Relações Internacionais do Centro Universitário Unieuro

ISSN: 1809-1261

UNIEURO, Brasília, número 13, 2014, pp 99-128.

Os recursos destinados às linhas de crédito que compõe o Pronaf Verde ainda são incipientes e pequenas em relação ao Pronaf Geral. Conforme registro da figura 1.7 o Pronaf Geral na safra 2010-2011 destinou 15 bilhões de reais, e a somatória de todos os recursos do Pronaf Verde resultou $\mathrm{R} \$ 315,1$ milhões desde a criação de todas as linhas de crédito.

O número de contratos operacionalizados na prática de cada linha de crédito é uma variável importante para análise da efetividade da política. No caso do Pronaf Verde composto de quatro linhas de crédito é delineado no Quadro 3 abaixo, que especifica a contratação entre 2004 a 2009 e o valor total contratado.

Quadro 3: Número de contratos do PRONAF Verde

\begin{tabular}{|ccccc|}
\hline & $\begin{array}{c}\text { Agroecol } \\
\text { ogia }\end{array}$ & Eco & ta & árido \\
\hline 2004 & - & - & 1758 & 3059 \\
2005 & 59,00 & - & 3339 & 10141 \\
2006 & 260,00 & - & 5356 & 10300 \\
2007 & 191,00 & 204 & 2248 & 7773 \\
2008 & 393,00 & 1386 & 1307 & 4105 \\
2009 & 76,00 & 1436 & 919 & 2742 \\
\hline Total & $\mathbf{5 7 0 5 2}$ Contratos \\
\hline
\end{tabular}

Fonte de Dados: MDA/SAF (2011)

De acordo com a Figura 1.6 o percentual de contratação dos créditos do Pronaf Geral vem aumentando significativamente, porém os resultados não são satisfatórios quando se analisa a efetividade da política pública. Vários fatores contribuem para negativamente para esses resultados, como por exemplo, a falta de informação, falta de formação e novas metodologias para contratação de crédito diferenciado por parte dos agentes financeiros entre outros. 


\section{Artigo original}

Hegemonia - Revista Eletrônica de Relações Internacionais do Centro Universitário Unieuro

ISSN: $1809-1261$

UNIEURO, Brasília, número 13, 2014, pp 99-128.

No Quadro 3 temos um total de 57.052 contratos realizados entre 2004 e 2009 pelas linhas de créditos que compõe o Pronaf Verde, confirmando os resultados incipientes do Quadro 2, onde recursos e contratos têm pouca representatividade em relação ao Pronaf Geral, que representou um somatório entre 2004-2009 de 11.281.201,16 contratos.

Na Figura 1.9 abaixo é possível acompanhar a conjuntura evolutiva dos contratos efetivados por linha de crédito.

Figura 1.9 Contratos efetivados da composição do Pronaf Verde

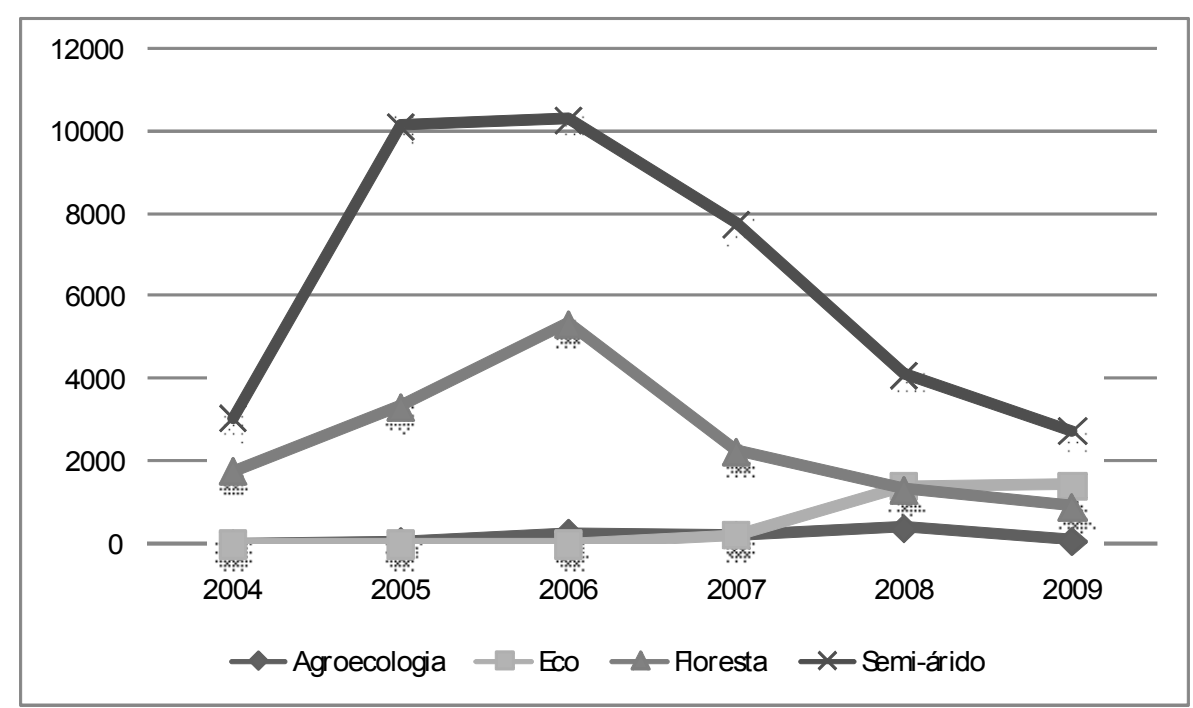

Fonte: Dados SAF/MDA (2011)

Verifica-se uma evolução nos contratos entre as safras 2004 a 2006, onde se destacaram o Pronaf Eco e o Pronaf Semi-árido, onde essa inclinação se deve ao fato da data de criação de cada programa, sendo a linha Pronaf Eco foi efetivada em 2007, mostrando um resultado positivo a partir desse ano.

A partir de uma análise regional dos dados, podem-se compreender algumas convergências e divergências que ocorrem políticas públicas nacionais e tem efeitos regionalizados diferenciados. 
Artigo original

Hegemonia - Revista Eletrônica de Relações Internacionais do Centro Universitário Unieuro

ISSN: $1809-1261$

UNIEURO, Brasília, número 13, 2014, pp 99-128.

No caso do Programa de Fortalecimento da Agricultura Familiar, as diferenças regionais são significantes, na Figura 2 a divisão regional é analisada.

Figura 2 Percentual de contratos do Pronaf efetivados por macrorregião

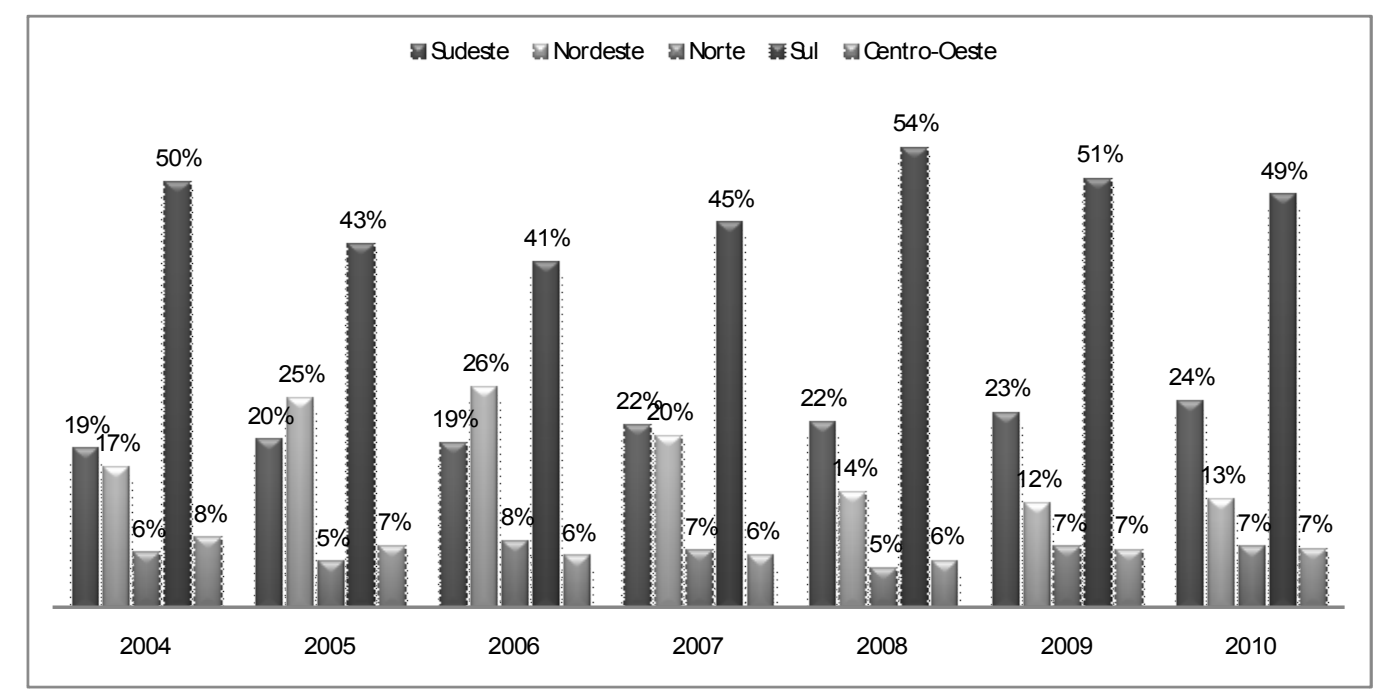

Fonte: Banco Central do Brasil (2011)

Além do percentual de contratos do Pronaf geral efetivados por região mostrada na Figura 2, a Figura 2.1 confirma a hegemonia da Região Sul na cultura empreendedora na área agrícola, mantendo uma média de $50 \%$ do total dos contratos entre 2004 e 2010, os produtores sulistas concentram seus esforços também no montante de recursos aplicados. 
Artigo original

Hegemonia - Revista Eletrônica de Relações Internacionais do Centro Universitário Unieuro

ISSN: $1809-1261$

UNIEURO, Brasília, número 13, 2014, pp 99-128.

Figura 2.1 Valores financiados: total e por macrorregião do Pronaf

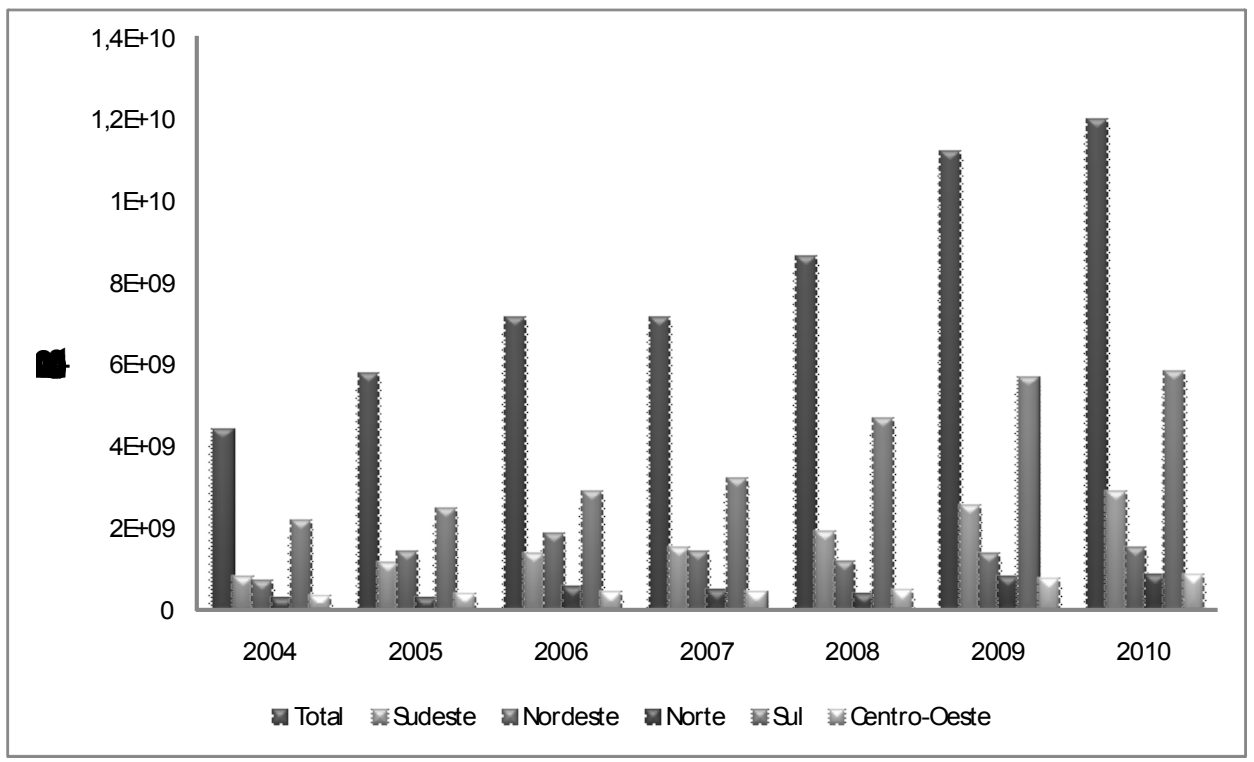

Fonte: Banco Central do Brasil (2011)

No caso do Pronaf Verde não há mudanças na conjuntura regional dos contratos e valores financiados. O deslocamento dos recursos se volta para regiões com características próprias da agricultura familiar, sendo a Região Sul ainda a macrorregião com maior aporte de recursos e contratos.

Conforme a Figura 2.2 e 2.3 apesar de poucos recursos, os fatores determinantes para a utilização dos montantes do Pronaf Verde continuam os mesmos do Pronaf Geral ou convencional. 
Artigo original

Hegemonia - Revista Eletrônica de Relações Internacionais do Centro Universitário Unieuro

ISSN: $1809-1261$

UNIEURO, Brasília, número 13, 2014, pp 99-128.

Figura 2.2 Número de contratos do Pronaf Verde por Região

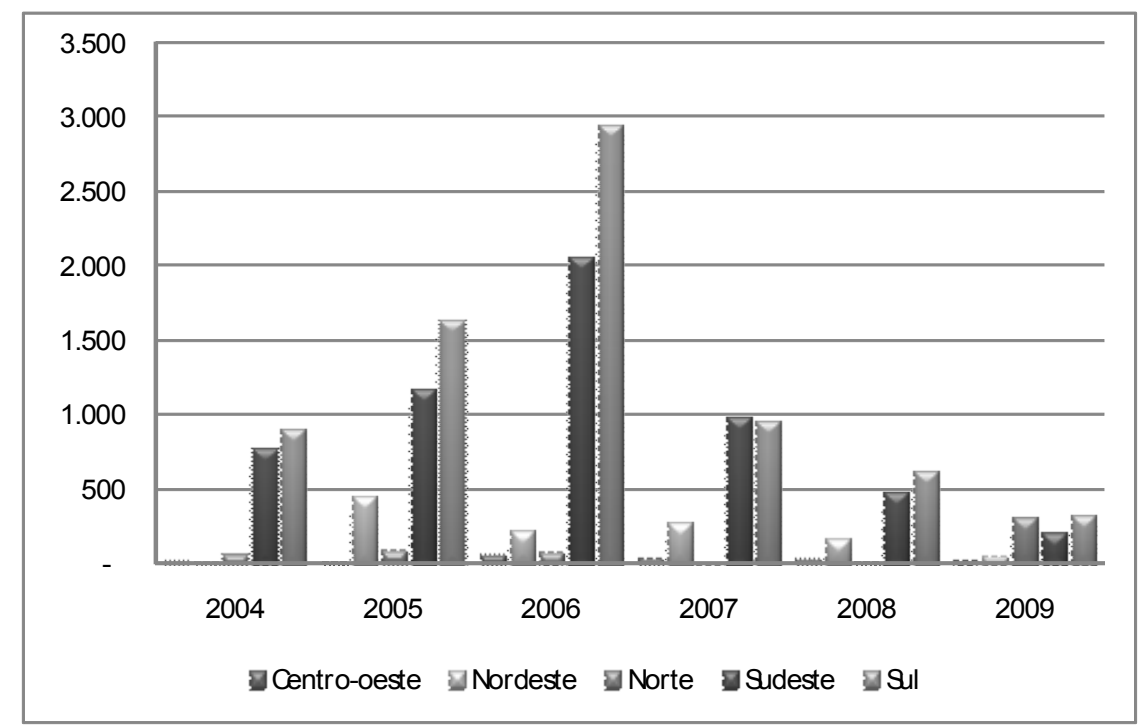

Fonte: Dados SAF/MDA (2011)

A Região Sul se destaca juntamente com a Região Sudeste na aquisição contratual dos recursos oriundos das linhas de crédito que compõe o Pronaf Verde. Porém em 2009 temos um equilíbrio entre as macrorregiões brasileiras. Na Figura abaixo a analise recai sobre a distribuição espacial dos valores destinados e utilizados regionalmente. 
Artigo original

Hegemonia - Revista Eletrônica de Relações Internacionais do Centro Universitário Unieuro

ISSN: $1809-1261$

UNIEURO, Brasília, número 13, 2014, pp 99-128.

Figura 2.3 Valores financiados do Pronaf Verde por Região

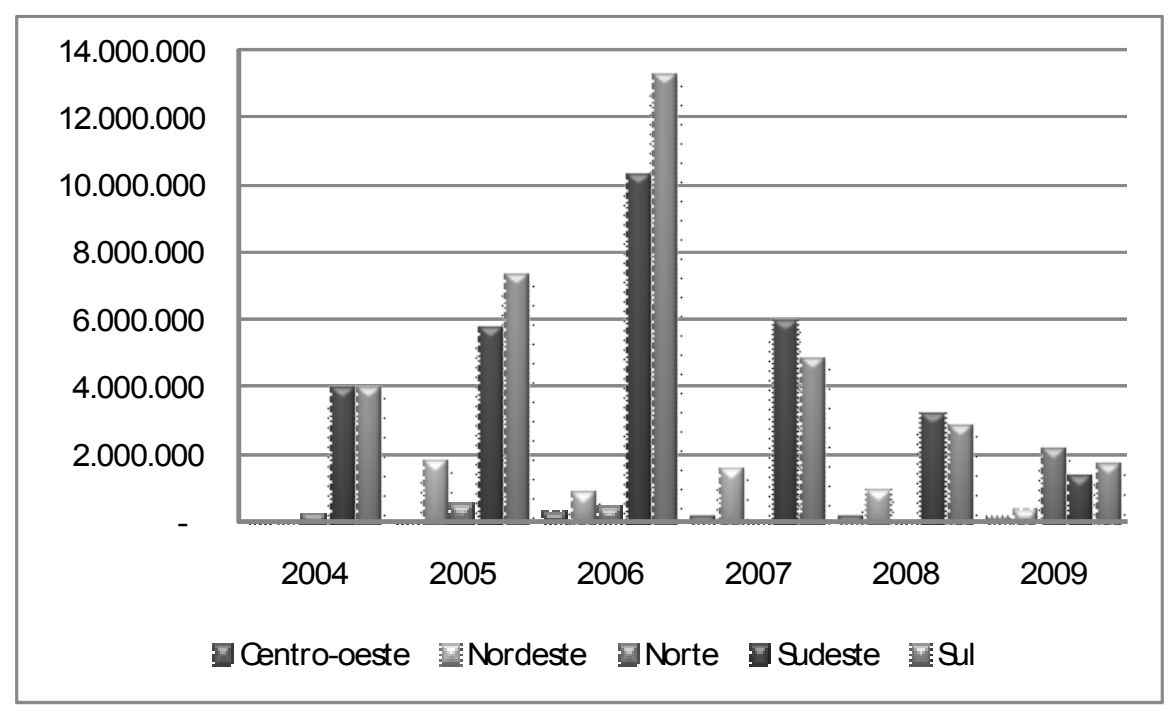

Fonte: Dados SAF/MDA (2011)

Os valores financiados condizem com a posição espacial dos contratos discutidos na Figura 2.2, prevalecendo novamente na Figura 2.3 à força empreendedora, produtiva e organizacional dos produtores da Região Sul e da Região Sudeste que conseguem utilizar os maiores volumes disponibilizados pelo Pronaf Verde.

Os resultados resumem a importância do crédito agrícola para o segmento produtivo de base econômica familiar, porém conforme objetivo do estudo, a análise do pool de linhas de créditos diferenciadas chamada de Pronaf Verde é uma iniciativa importante, que precisa de inovações estruturais capazes de provocar uma nova revolução verde que não tenha somente a tecnologia como base de apoio, mas a consciência coletiva do uso dos recursos naturais. A classe produtiva agrícola precisa de apoio creditício inevitavelmente, mas precisa também de auxilio gerencial para conseguir adequar-se a práticas e investimentos sustentáveis. As práticas conservacionistas preteridas pelo uso do crédito verde requerem não apenas recursos financeiros requerem apoio técnico para saber utilizar os 
Artigo original

Hegemonia - Revista Eletrônica de Relações Internacionais do Centro Universitário Unieuro

ISSN: $1809-1261$

UNIEURO, Brasília, número 13, 2014, pp 99-128.

recursos através da formação de agentes de desenvolvimento local preparados para apoiar o produtor familiar.

De acordo com Sambuichi e Oliveira (2011) vários fatores podem explicar o baixo desempenho das linhas de crédito associadas aos modelos sustentáveis de produção agropecuária familiar. A dificuldade de acesso ao crédito junto aos bancos, os quais não estariam devidamente preparados para analisar e aprovar projetos agrícolas não convencionais, especialmente projetos agroecológicos. Os problemas relativos à liberação do crédito pelos bancos passam desde a normatização inadequada das planilhas, que não foram preparadas para sistemas de produção muito diversificados, o desconhecimento por parte dos funcionários dos bancos sobre o funcionamento dessas linhas, a morosidade dos processos, até a resistência dos bancos em financiar pequenos projetos de baixa rentabilidade.

Por outro lado, são citados também problemas como a falta de conhecimento dos agricultores sobre a existência e funcionamento dessas linhas de crédito e a falta de assistência técnica capacitada para auxiliar na elaboração de projetos agrícolas não convencionais (FERRARI E ABRÃ̃O, 2008).

5. Considerações finais

Com o objetivo de analisar a nova política de crédito rural para o desenvolvimento da agricultura familiar sustentável, esse estudo proporcionou uma nova abordagem para a promoção de uma política de crédito sustentável. A construção de uma nomenclatura diferenciada para um conjunto de linhas de créditos rurais revelou uma análise conjuntural 
Artigo original

Hegemonia - Revista Eletrônica de Relações Internacionais do Centro Universitário Unieuro

ISSN: 1809-1261

UNIEURO, Brasília, número 13, 2014, pp 99-128.

quantitativa e qualitativa que resultou em novos desafios para o setor produtivo e para a política agrícola nacional.

Concluiu-se através dos dados que os esforços efetuados em relação ao Pronaf foram intensos e com aporte recursal de grande proporção. A política de crédito nacional percebeu sua importância para o setor agropecuário e acionou subsídios importantes para o crescimento setorial.

Nesses moldes as regras do jogo mudaram e novas expectativas foram traçadas após as pressões causadas pelas mudanças climáticas, 0 crédito como aporte do crescimento deveria ser inovado, e foi de alguma forma. Com o advento das novas linhas de crédito Pronaf Agroecologia, Pronaf Eco, Pronaf Semi-árido e Pronaf Eco criados a partir de 2003 o Governo Federal através do Ministério do Desenvolvimento Agrário e sua Secretaria de Agricultura Familiar entenderam que há um elo entre o uso de recursos financeiros e o uso dos recursos naturais.

Com o nome de Pronaf Verde o pool de linhas de crédito mostrouse ainda incipientes em relação ao montante do Pronaf Total. Alguns desafios devem ser solucionados para garantir o uso do Pronaf Verde em grande escala, resultando em um desenvolvimento agrícola pautada pela sustentabilidade das áreas produtivas. O Pronaf Verde é uma abordagem pode caracterizar uma nova institucionalidade no setor agropecuário, proporcionando a utilização de sistemas de produção capazes de garantir a alimentação da população, o uso correto dos recursos naturais e a garantia de subsistência dos produtores rurais de base econômica familiar. 
Artigo original

Hegemonia - Revista Eletrônica de Relações Internacionais do Centro Universitário Unieuro

ISSN: 1809-1261

UNIEURO, Brasília, número 13, 2014, pp 99-128.

Referências bibliográficas

CHARLES, H; GODFRAY, BEDDINGTON, J.R. et al. Food Security: The Challenge of Feeding 9 Billion People. Science, vol. 327, Feb. 2010. p. $812-818$.

FAO. The State of Agricultural Commodity Markets 2009: High food prices and the food crisis - experiences and lessons learned. FAO, Roma, 2009a. 68 p. Disponível em < http://www.fao.org/docrep/012/i0854e/i0854e00.htm>. Acesso em Janeiro de 2010.

FERRARI, E. A.; ABRAAO, S. S. Pronaf Agroecología: sistematización de una experiencia llevada a cabo en la Zona da Mata de Minas Gerais. In: Gabriela Scotto. (Org.). Aun hay tiempo para el sol. Pobrezas rurales y programas sociales: Brasil, Venezuela, Guatemala. Una mirada desde lo local. 1 ed. Rio de Janeiro: Action Aid - Oficina Regional Américas, 2008, v. 1 , p. 65-89.e

FEDOROFF, N.V.; BATTISTI, D.S.; BEACHY, R.N. et al. Radically Rethinking Agriculture for the 21st Century. Science, vol. 327, Feb. 2010. p. $833-834$.

GUALDA, N. L. P. Agricultura familiar versus modelo agro-exportador: o falso dilema da coexistência. Texto de Discussão. Maringá: UEM, 2006.

GUANZIROLI, C.E; CARDIM, S.E. Novo Retrato da Agricultura Familiar: O Brasil Redescoberto. Brasília, INCRA : FAO, Março de 2002. 
Artigo original

Hegemonia - Revista Eletrônica de Relações Internacionais do Centro Universitário Unieuro

ISSN: $1809-1261$

UNIEURO, Brasília, número 13, 2014, pp 99-128.

MDA - Ministério do Desenvolvimento Agrário. Estatísticas do meio rural.

Departamento Intersindical de Estatística e Estudos Socioeconômicos; Núcleo de Estudos Agrários e Desenvolvimento Rural. 2 Ed., Brasília : MDA : DIEESE, 2006. 276 p.

MDA - Ministério do Desenvolvimento Agrário. Agricultura familiar no Brasil e o censo agropecuário de 2006. MDA, Brasília, 2009, p. 14. Disponível em:

http://portal.mda.gov.br/portal/saf/arquivos/view/arquivosdestaque/censo 2006.pdf>. Acesso em Abril de 2010.

SAMBUiCHI, R. H. R.; OLIVEIRA, M. A. C. Análise das linhas de crédito do PRONAF para o desenvolvimento sustentável da agricultura familiar. Cadernos de Agroecologia -Fortaleza, 2011.

TESTER, M.; LANGRIDGE, P. Breeding Technologies to Increase Crop Production in a Changing World. Science, vol. 327, Feb. 2010. p. 818 822.

THE WORLD BANK. Global World development report 2008: agriculture for development - overview. The International Bank for Reconstruction and Development ; The World Bank Group; Washington; Trade Note 34; July 24, 2008. 36 p.

VILPOUX, O. F.; OLIVEIRA, M. A. C.; Evolução da produtividade da agropecuária no Brasil e no mundo: influencia da agricultura familiar e dos mercados de exportação. Anais do Congresso SOBER, 2010. 
Artigo original

Hegemonia - Revista Eletrônica de Relações Internacionais do Centro Universitário Unieuro

ISSN: $1809-1261$

UNIEURO, Brasília, número 13, 2014, pp 99-128.

VILPOUX, O. F.; OLIVEIRA, M. A. C.; Governanças na agricultura familiar: mercados, contratos, redes e cooperativismo. In: Sustentabilidade e Agricultura Familiar, Editora CRV: Curitiba, 2011.

WILKINSON, J. Mercados, Redes e Valores. Porto Alegre: UFRGS, 2008. 